\title{
Spatio-Temporal Distribution of Southeastern Community Forests in Togo (West Africa)
}

\section{Yawo Konko1 ${ }^{*}$, Jean Paul Rudant ${ }^{2}$, Gbétey Kokouvi Akpamou ${ }^{3}$, Koffi Dodji Noumonvi4, Kouami Kokous 5}

\author{
${ }^{1}$ National Environmental Observatory, National Agency of Environment Management, Lomé, Togo \\ ${ }^{2}$ LaSTIG/IGN, MATIS, Radar Remote Sensing Group, Paris-Est Marne la Vallée University, Paris, France \\ ${ }^{3}$ Department of Studies and Planning, Ministry of Environment and Forest Resources, Lomé, Togo \\ ${ }^{4}$ Higher Institute of Agronomy, University of Lisbon, Lisbon, Portugal \\ ${ }^{5}$ Laboratory of Forest Research, Faculty of Sciences, University of Lomé, Lomé, Togo \\ Email: *konkoyawo2@gmail.com
}

How to cite this paper: Konko, Y., Rudant, J.P., Akpamou, G.K., Noumonvi, K.D. and Kokou, K. (2018) Spatio-Temporal Distribution of Southeastern Community Forests in Togo (West Africa). Journal of Geoscience and Environment Protection, 6, 51-65.

https://doi.org/10.4236/gep.2018.67004

Received: May 30, 2018

Accepted: July 8, 2018

Published: July 11, 2018

Copyright (C) 2018 by authors and Scientific Research Publishing Inc. This work is licensed under the Creative Commons Attribution International License (CC BY 4.0)

http://creativecommons.org/licenses/by/4.0/

\begin{abstract}
The present study aimed to provide the basics needed to reconcile the fight against poverty with the need of a good management of community resources in the context of local and sustainable development. It focused on the identification of geographic location and spatio-temporal dynamics of these resources in the southeastern part of Togo. The methodological approach was based on the spatial analysis of the area for the years 1988, 2000 and 2018 by combining optical imagery from Landsat TM, ETM+ and Sentinel-2A MSI satellites with radar imagery from Sentinel-1A IW/GRDH. Spatial analysis showed a fragmented spatial structure undergoing major changes for the period 1988-2018. Plantations, riparian formations, agglomerations, water bodies and wetlands increased respectively by $4.61 \%$, $2.09 \%, 1.07 \%, 0.43 \%$ and $0.35 \%$ annually, while forests, savannahs, crops and fallow lands decreased annually by $0.71 \%, 5.87 \%$ and $1.97 \%$. For the "forests" class, seven community forests geographically organized in three sub-groups were identified and mapped. The analysis of their areas pointed to the fact that out of 667 ha of community forests in 1988, only 415 ha remain in 2018, which means a loss of $37.78 \%$ in forest areas over the 30 years, or an annual deforestation rate of $1.64 \%$. The different spatial changes observed could be attributed to several unsustainable human activities. The land use maps for the years 1988, 2000 and 2018 will contribute to resource localization and protection in sensitive areas or, in other words, to the integrated and rational management of these resources. The different identified and mapped community forests could serve as management units for managers in developing their management plans.
\end{abstract}




\section{Keywords}

Landsat Image, Sentinel Image, Spatial Analysis, Community Forest, Lower Mono Valley

\section{Introduction}

Forest management planning in Togo began since the colonial era and resulted in the creation of 83 protected areas [1]. Over time, these protected areas have unfortunately been managed unilaterally and repressively by the forestry administration, leading to an alienation of the rights of local communities. This situation hindered the application of regulatory texts governing the conservation of biological resources, and led to a loss in forest areas because of human activities [2] [3] [4].

In order to correct this situation and involve local populations in the conservation and management of forest resources, several policies, strategies and programs have been developed leading for instance to the introduction of the concept of Community Forests (CF) through the law No. 011 of March 13, 2007 on the decentralization and local liberty policy [5]. This law proposed a favorable legal framework that allows local communities to manage, in a consensual manner with the administration, individual properties by offering them the opportunity to enjoy all the benefits they can derive from it. Individuals are defined by the Forest Code of 2008, as natural or legal persons, rural or basic communities or groups that do not fall into the category of local authorities. The CF approach is effective by empowering communities to undertake economic activities aimed at reducing poverty, improving living conditions and ensuring local development [6] [7].

The approach has already proven to be effective, as more than ten CFs have been implemented. The extension of the approach throughout the Togolese territory requires the localization of the resources, their characterization and the identification of opportunities they can offer for local development.

In southeastern Togo, and more specifically in the Lower Mono Valley (LMV), the characteristic vegetation formations of wetlands, including mangroves, semi-deciduous forests and floodable savannahs with Mitragyna inermis, are of major importance. The ecological conditions (important hydrographic network and clay soils, flooded almost every year), making the soils difficult to farm, are still assets for the durability of these community forests. However, the area is highly vulnerable since it is subject to deforestation driven by the need of fuelwood of an increasing population. The constant search for appropriate solutions to the problem of recurrent poverty is pushing local communities to exert uncontrolled pressure on local natural resources. Therefore, the adequacy between the population growth rate and the degradation of forest resources raises questions about the distribution of community forest resources in the LMV and 
changes they have undergone during the last three decades.

To answer these questions, the present study is based on the assumption that local communities of the LMV still have the capacity to protect a large part of the forest resources of their land, despite the problems of population growth and resource degradation that they are facing. Based on remote sensing techniques, such as the combination of optical and Radar satellite imagery, this study aims to provide the basic elements needed to reconcile the fight against poverty and the need of a good management of CFs of the LMV through the principles of sustainable forest management. Specifically, it involves studying and monitoring the spatio-temporal dynamics of the LMV community resources using satellite imagery.

\section{Materials and Methods}

\subsection{Study Area}

The Lower Mono Valley (LMV) is located south of the Mono Transboundary Biosphere Reserve (http://www.unesco.org/) in southeastern Togo. With an average area of 107,486 ha, it lies between latitudes $6^{\circ} 14^{\prime} 32,921^{\prime \prime}$ and $6^{\circ} 41^{\prime} 24,013^{\prime \prime}$ North and longitudes $1^{\circ} 24^{\prime} 6018^{\prime \prime}$ and $1^{\circ} 48^{\prime} 30,631^{\prime \prime}$ East (Figure 1). The terrain is slightly rugged, but dominated by vast plains. The pedology is characterized by poorly developed soils, vertisols, and soils rich in iron sesquioxides [8]. In terms of climate, the LMV benefits from the Guinean tropical regime characterized by an alternation of two rainy seasons and two dry seasons, well distinct and of unequal lengths. The annual rainfall varies between 1000 and $1400 \mathrm{~mm}$ /year. The average temperature is generally high, around $27^{\circ} \mathrm{C}$ in the coastal zone [5].

\subsection{Data Acquisition}

The data used in this study are satellite data obtained through passive (optical) and active (Radar) remote sensing. Optical images (Landsat TM, ETM+, https://landsat.usgs.gov/; Sentinel-2A MSI, https://sentinel.esa.int/) were selected based on their availability and a cloud cover rate of less than 5\%. Apart from differences in resolution between the three sensors (Table 1), there are also differences in bands. In fact, TM consists of seven bands; ETM+ has a panchromatic band in addition to those of TM; MSI has 13 bands. Whereas Landsat TM and ETM+ include a thermal band, Sentinel-2 MSI does not include a thermal band. The choice of Radar images (Sentinel-1A, https://sentinel.esa.int/) was based on seasons of the year (short and long rainy seasons, small and long dry seasons), given the fact that the Radar echo can be influenced by surface properties (Table 2).

\subsection{Pre-Processing of Optical Images}

The preprocessing of optical images was done under the SNAP (Sentinel Application Platform) software [9]. It included contrast enhancement, resampling and mosaicking of images. Subsequently, in order to improve the discrimination of 


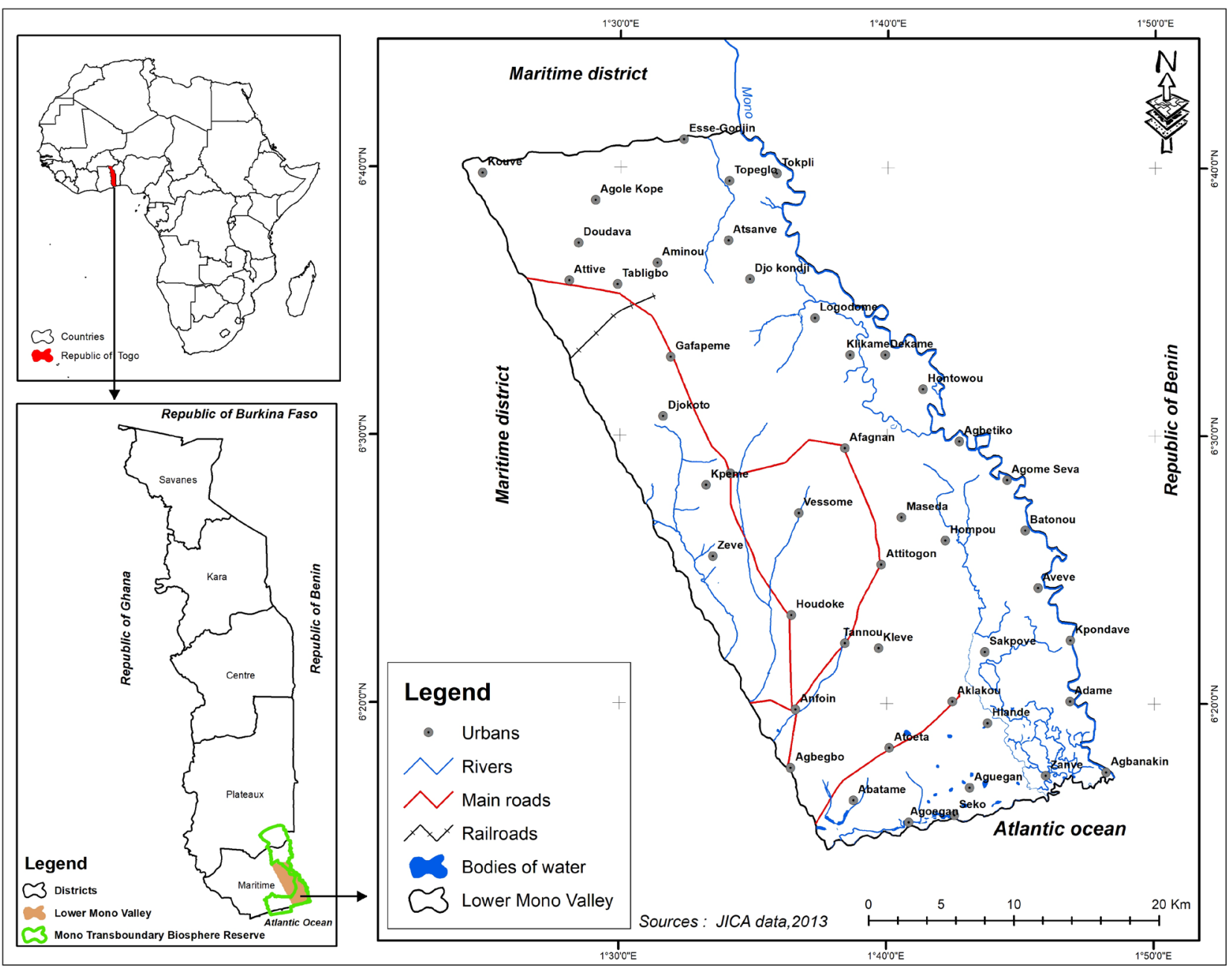

Figure 1. Geographic location of the lower mono valley.

Table 1. Characteristics of optical satellite images.

\begin{tabular}{cccccccc}
\hline $\mathbf{N}^{\circ}$ & Satellite & Sensor & $\begin{array}{c}\text { Number of } \\
\text { bands }\end{array}$ & Path/Row & $\begin{array}{c}\text { Spatial } \\
\text { resolution }\end{array}$ & Sensing date Cloud cover \\
\hline $\mathbf{1}$ & Sentinel-2A & MSI & 13 & - & $10(10-60)$ & $04 / 01 / 2018$ & $0 \%$ \\
$\mathbf{2}$ & Landsat 7 & ETM+ & 8 & $192 / 056$ & $30(15-30)$ & $13 / 12 / 2000$ & $2 \%$ \\
$\mathbf{3}$ & Landsat 7 & ETM+ & 8 & $192 / 055$ & $30(15-30)$ & $13 / 12 / 2000$ & $2 \%$ \\
$\mathbf{4}$ & Landsat 4 & TM & 7 & $192 / 056$ & $30(30)$ & $12 / 02 / 1988$ & $1 \%$ \\
$\mathbf{5}$ & Landsat 4 & TM & 7 & $192 / 055$ & $30(30)$ & $12 / 02 / 1988$ & $1 \%$ \\
\hline
\end{tabular}

Table 2. Characteristics of radar satellite images.

\begin{tabular}{lccccccc}
\hline $\mathrm{N}^{\circ}$ & Satellite & Mode & Polarization & $\begin{array}{c}\text { Spatial } \\
\text { resolution } \\
\left(\mathrm{m}^{2}\right)\end{array}$ & $\begin{array}{c}\text { Wave length } \\
(\mathrm{cm})\end{array}$ & $\begin{array}{c}\text { Sensing } \\
\text { date }\end{array}$ & $\begin{array}{c}\text { Season of } \\
\text { the year }\end{array}$ \\
\hline 1 & Sentinel-1A & IW/GRDH & $\mathrm{VV} / \mathrm{VH}$ & $20 \times 22$ & $\lambda=5.6$ & $20 / 06 / 2017$ & Long rainy \\
\hline
\end{tabular}




\section{Continued}

$\begin{array}{llllllll}2 & \text { Sentinel-1A } & \text { IW/GRDH } & \text { VV/VH } & 20 \times 22 & \lambda=5.6 & 19 / 08 / 2017 & \text { Short dry } \\ 3 & \text { Sentinel-1A } & \text { IW/GRDH } & \text { VV/VH } & 20 \times 22 & \lambda=5.6 & 05 / 10 / 2017 & \text { Short rainy } \\ 4 & \text { Sentinel-1A } & \text { IW/GRDH } & \text { VV/VH } & 20 \times 22 & \lambda=5.6 & 04 / 12 / 2017 & \text { Long dry }\end{array}$

land use units through photointerpretation, two indices were calculated from the satellite images: The Normalized Difference Vegetation Index (NDVI) [10] and the Normalized Difference Water index (NDWI) [11]. These two indices were calculated as in Equations (1) and (2) where NIR is the Near Infrared channel, MIR is the mid wave infrared channel and $\mathrm{R}$ is the red channel.

$$
\begin{gathered}
\mathrm{NDWI}=(\mathrm{NIR}-\mathrm{MIR}) /(\mathrm{NIR}+\mathrm{MIR}) \\
\mathrm{NDVI}=(\mathrm{NIR}-\mathrm{R}) /(\mathrm{NIR}+\mathrm{R})
\end{gathered}
$$

\subsection{Pre-Processing of Radar Images}

Sentinel-1A Radar images were pre-processed with Sentinel 1 software. Pretreatments included geometric correction, radiometric calibration, speckles filtering using a Lee filter [12] and orthorectification. The orthorectification was performed using the Range Doppler Terrain Correction algorithm [9] and an ASTER (Advanced Spaceborne Thermal Emission and Reflection Radiometer) Digital Terrain Model. Afterwards, complementary images such as color composite images and resultant images $(\mathrm{VV}+\mathrm{VH})$, both filtered and at full spatial resolution, were produced and converted to decibel [13] to allow an easier discrimination of land use classes.

\subsection{Visual Interpretation}

The optical and radar images as well as the different indices were interpreted visually based on spectral signatures, field visits and Google Earth images. The 1956 African vegetation typology proposed by Yangambi [14] was used, with some adaptation, for naming the different land uses. Following the image interpretation, Sentinel 2A satellite sensors proved to have a better scene rendering compared to Landsat (TM/ETM +) sensors. For the filtered radar images, the color composite images allowed a better identification of land use classes compared to the VV and $\mathrm{VH}$ polarized images and resultant images $(\mathrm{VV}+\mathrm{VH})$. The visual interpretation of both optical and radar images made it possible to define an interpretation key for the classification of optical images.

\subsection{Classification of Optical Images}

The interpretation key helped define training zones by creating ROIs (Region of Interest, defining land use classes) under OrfeoToolBox (OTB). Subsequently, a supervised classification was performed using the Support Vector Machine (SVM) algorithm. This algorithm was chosen for its efficiency in classifying complex landscapes and producing good results [15]. It also performs better 
than many other methods of classification of satellite images [16] [17]. SVM is a statistical learning classification technique. SVM focuses classification decisions on the boundary between classes instead of their mean and variance values [18].

\subsection{Quality Control of the Classification}

The validation of the classification was carried out through 160 control points randomly selected and distinct from the ROIs, 20 points per land use class. Ground truth was obtained through field visits and Google Earth images. By confronting the classified images with ground truth, confusion matrices, Kappa indices $(\mathrm{K})$ and the global precision were computed as in [19], for the years 1988, 2000 and 2017. The kappa index is used in image classification as a metrics of the agreement between the classification results and ground truth [20]. According to the scale of Landis and Koch [21], the classification is considered excellent if $\mathrm{K}$ is greater than 0.8 , good if $\mathrm{K}$ is between 0.8 and 0.6 , moderate when $\mathrm{K}$ ranges from 0.6 to 0.2 and bad when $\mathrm{K}$ is less than 0.2 . Shapefiles and area of each landuse were obtained through the vectorization of the classified images.

\subsection{Spatio-Temporal Land Use Change}

The classified and validated optical images were synchronized under the SNAP software. This synchronization allowed the visualization and mapping of some of the changes that occurred between 1988 and 2018. Subsequently, a quantita-

tive analysis was performed based on the annual evolution rate ( $T_{\text {annual }}$, Equation (3)) [22]. $S_{1}$ and $S_{2}$ represent the area of a given land use, for the initial date and the final date respectively; $d$ is the number of years between the two dates.

$$
T_{\text {annual }}=\left(S_{2}-S_{1}\right) /(d \times 100)
$$

For the CFs, the deforestation rate $(\theta)$ was considered instead, because it is specific to forests and takes into account cleared land. The standardized formula proposed by Puyravaud [23] was applied as in Equation (4). $\mathrm{A}_{1}$ and $\mathrm{A}_{2}$ represent forest areas respectively for the initial year and the final year. $T_{1}$ and $T_{2}$ correspond to the exact acquisition dates of the satellite images respectively for the initial year and the final year.

$$
\theta=-100 /\left(T_{2}-T_{1}\right) \times \ln \left(A_{2} / A_{1}\right)
$$

\section{Results}

\subsection{Quality Control of the Classification}

The control of the classification of TM and ETM+ optical images gave an overall accuracy of $84.54 \%$ and $86.31 \%$ respectively. The Kappa index (K) calculated was 0.81 and 0.83 for the years 1988 and 2000. The control of the classification of the MSI image of 2018 showed that 147 out of the 160 randomly selected points were accurately assigned to their actual land use. This generated an overall accuracy of $91.57 \%$ and a Kappa index of $90.03 \%$ (Table 3). 
Table 3. Confusion matrix for the quality control of the classification.

\begin{tabular}{cccccccccc}
\hline & \multicolumn{10}{c}{ Classified image } \\
\hline Ground truth & UR & BW & FO & RI & SA & PL & SW & CF & To \\
UR & 93.76 & 0.00 & 0.00 & 0.00 & 0.00 & 0.00 & 0.00 & 6.24 & 100.00 \\
BW & 0.04 & 91.52 & 0.00 & 0.00 & 0.00 & 8.48 & 0.00 & 0.00 & 100.00 \\
FO & 0.00 & 0.00 & 89.45 & 3.00 & 6.00 & 1.55 & 0.00 & 0.00 & 100.00 \\
RI & 0.00 & 0.00 & 0.00 & 95.00 & 1.45 & 0.00 & 3.55 & 0.00 & 100.00 \\
SA & 0.00 & 0.00 & 4.50 & 2.00 & 90.55 & 0.00 & 2.95 & 2.96 & 100.00 \\
PL & 0.00 & 0.00 & 6.05 & 0.00 & 2.00 & 89.97 & 1.98 & 0.00 & 100.00 \\
SW & 0.00 & 7.48 & 0.00 & 0.00 & 0.00 & 0.00 & 91.52 & 0.00 & 99.00 \\
CF & 6.2 & 1.00 & 0.00 & 0.00 & 0.00 & 0.00 & 0.00 & 90.8 & 100.00 \\
To & 100.00 & 100.00 & 100.00 & 100.00 & 100.00 & 100.00 & 100.00 & 100.00 & \\
& Overall accuracy $=91.57 \%$, Kappa index $=90.03 \%$ & & \\
\hline
\end{tabular}

$\mathrm{UR}=\mathrm{Urban}$ areas, $\mathrm{BW}=$ Bodies of water, $\mathrm{FO}=$ Forests, $\mathrm{RI}=$ Riparian vegetation, $\mathrm{SA}=$ Savannahs, $\mathrm{PL}=$ Plantations, $\mathrm{SW}=$ Swamps, $\mathrm{CF}=$ Crops and Fallows, $\mathrm{To}=$ Total.

\subsection{Land Use Maps}

Figure 2 shows maps obtained from the classification of optical images for the three dates (1988, 2000 and 2018). In total, eight land cover classes were mapped. These are forests (forest patches, sacred forests, community forests, etc.), savannahs (wooded savannahs, savannahs with few trees, grassland savannahs), plantations (palm groves, coconut groves, teak plantations), riparian vegetation, body of water, swamps, urban areas, crops and fallows.

\subsection{Qualitative Analysis of Land Use Change}

The comparison of the classified images of 1988 and 2018 helped perform a qualitative analysis, in order to identify changes in land use and areas where they have occurred. Figure 3 is an illustration of some of the major changes. Overall, urban areas and plantations increased in area at the expense of forests and savannahs.

\subsection{Quantitative Analysis of Land Use Change}

The quantitative analysis assessed areas of land use change for the study period. In 1988 , the landscape of the region was dominated by crops and fallows (36.85\%), savannahs (28.08\%) and plantations (21.49\%). Between 1988 and 2018 , there was a decrease in the area of savannahs, crops and fallows, while an increase was identified for plantations and riparian formations (Table 4). The annual growth rate during this period for plantations, riparian formations, urban areas, body of water and marshy areas was $4.61 \%, 2.09 \%, 1.07 \%, 0.43 \%$ and $0.35 \%$ respectively. The annual decrease rate was $5.87 \%, 1.97 \%$ and $0.71 \%$ for savannahs, crops and fallows and forests respectively (Table 5). In 2018, the 


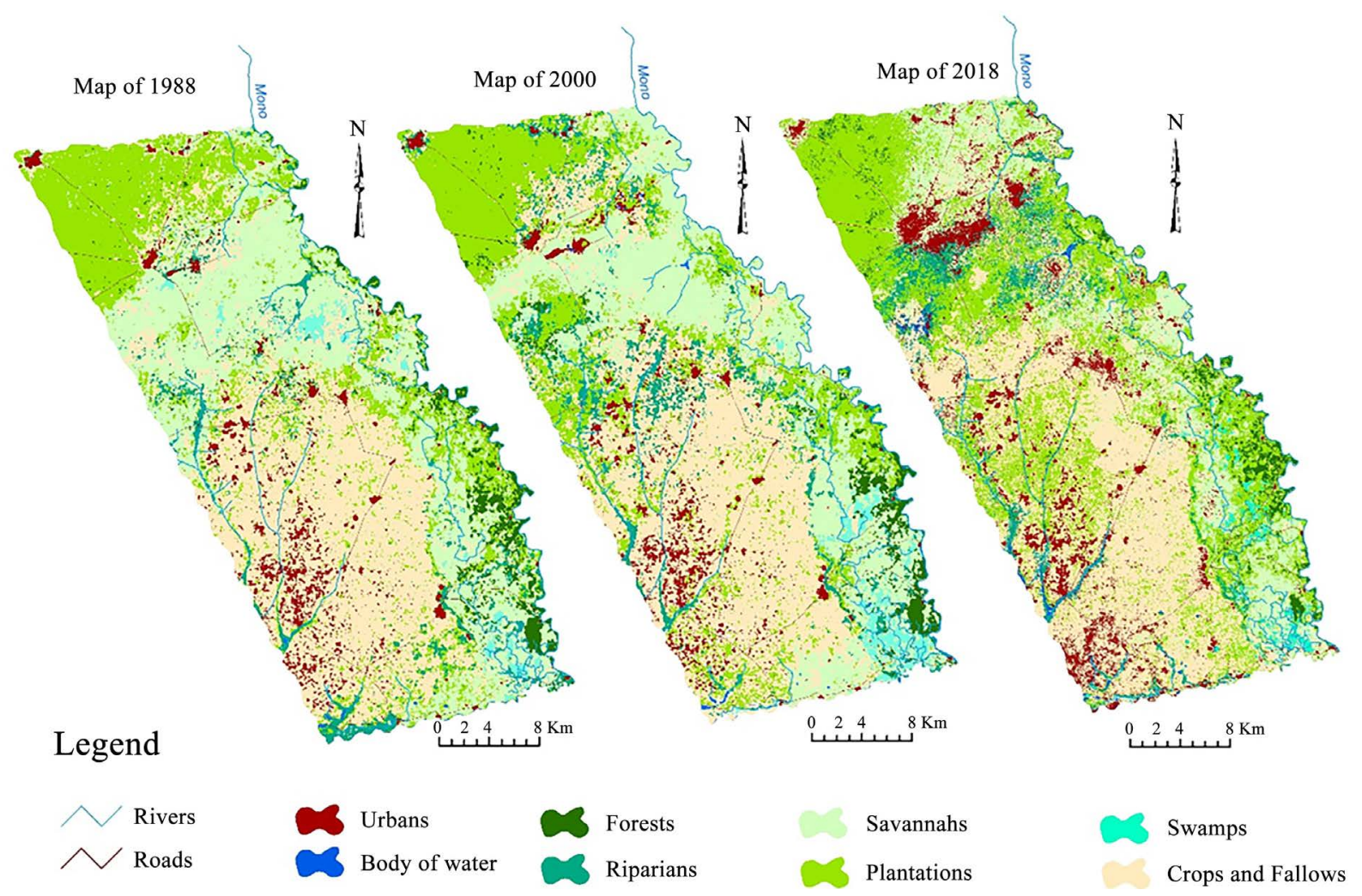

Figure 2. Land use maps for years 1988, 2000 and 2018.

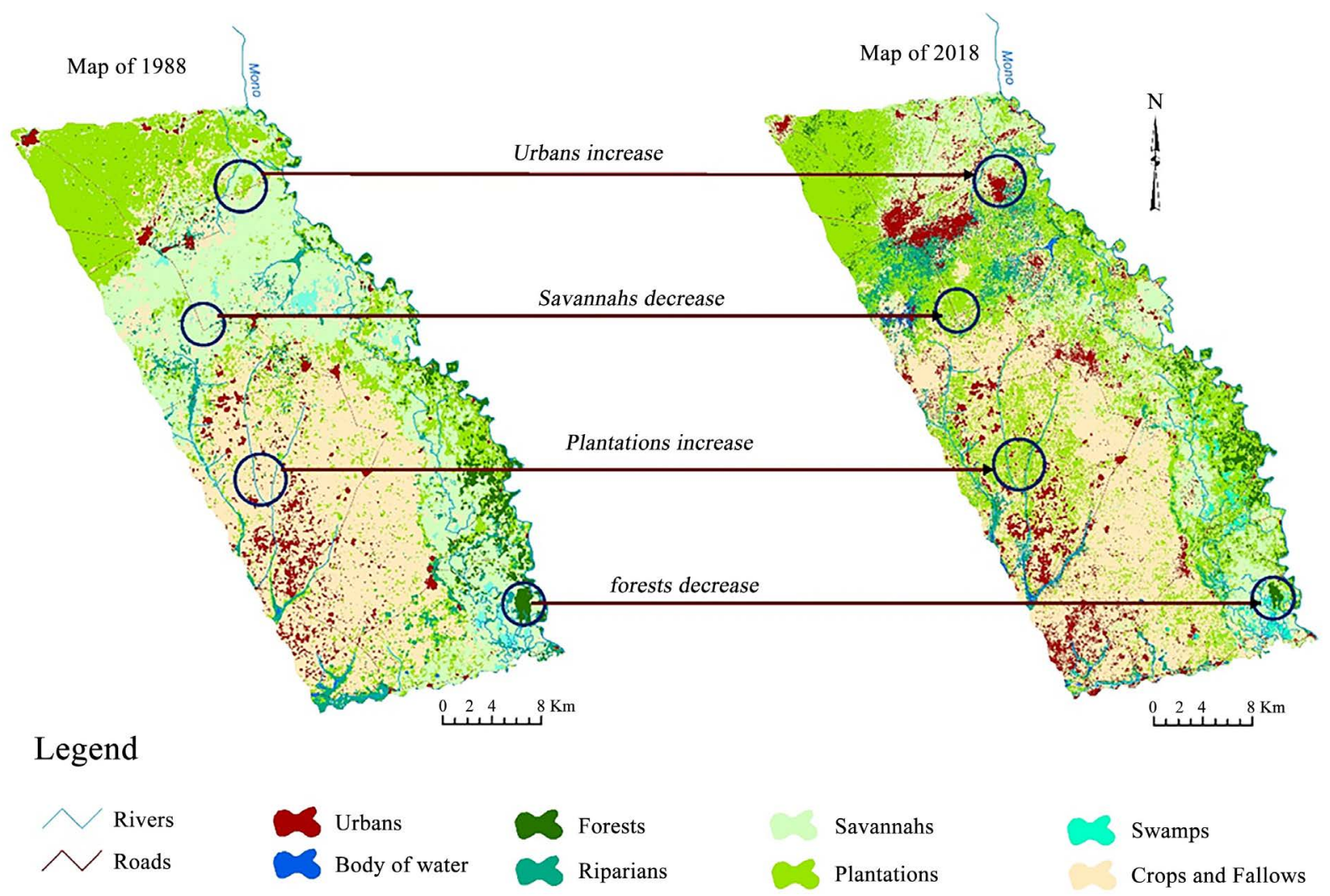

Figure 3. Overview of some of the major changes between 1988 and 2018. 
Table 4. Changes in area of the different land uses.

\begin{tabular}{ccccccc}
\hline \multirow{2}{*}{ Land use/Land cover } & \multicolumn{2}{c}{ Area 1988} & \multicolumn{2}{c}{ Area 2000} & \multicolumn{2}{c}{ Area 2018} \\
\cline { 2 - 7 } & ha & $\%$ & ha & $\%$ & ha & $\%$ \\
\hline Body of water & 295 & 0.27 & 940 & 0.88 & 1545 & 1.44 \\
Swamps & 1371 & 1.28 & 1873 & 1.75 & 2390 & 2.23 \\
Riparians & 5735 & 5.34 & 8771 & 8.17 & 11,795 & 10.99 \\
Forests & 3385 & 3.15 & 2350 & 2.19 & 1315 & 1.23 \\
Savannahs & 30,136 & 28.08 & 21,620 & 20.14 & 13,101 & 12.21 \\
Plantations & 23,070 & 21.49 & 29,739 & 27.71 & 36,440 & 33.95 \\
Crops and fallows & 39,549 & 36.85 & 36,703 & 34.2 & 33,848 & 31.54 \\
Urbans & 3792 & 3.53 & 5337 & 4.97 & 6899 & 6.43 \\
Total & 107,333 & 100 & 107,333 & 100 & 107,333 & 100 \\
\hline
\end{tabular}

Table 5. Annual rate of change (ARC) of the different land use classes.

\begin{tabular}{cccc}
\hline \multirow{2}{*}{ Land use/Land cover } & \multicolumn{3}{c}{ ARC (\%) } \\
\cline { 2 - 4 } & $1988-2000$ & $2000-2018$ & $1988-2018$ \\
\hline Body of water & 0.54 & 0.36 & 0.43 \\
Swamps & 0.42 & 0.3 & 0.35 \\
Riparians & 2.53 & 1.78 & 2.09 \\
Forests & -0.86 & -0.61 & -0.71 \\
Savannahs & -7.1 & -5.01 & -5.87 \\
Plantations & 5.56 & 3.94 & 4.61 \\
Crops and fallows & -2.37 & -1.68 & -1.97 \\
Urbans & 1.29 & 0.92 & 1.07 \\
\hline
\end{tabular}

landscape is mainly characterized by plantations (33.95\%), crops and fallows (31.54\%), savannahs (12.21\%) and riparian formations (10.99\%).

\subsection{Spatial Distribution of Community Forests}

Seven (7) semi-deciduous CFs geographically grouped into three (3) subgroups were identified and mapped. The first one is the Avélèbè community forest located on the eastern side of the town of Aveve near the Mono river. The second one includes the community forests of Amévo, Dougbanavé, Fontan and Mambui located on the western side of the city of Aveve. The third one includes the community forests of Akissa and Tètè Condji located southeast of the city of Adame near the Mono river (Figure 4).

\subsection{Spatio-Temporal Dynamics of Community Forests}

The change analysis of community forests (Figure 5) revealed that out of 667 ha 


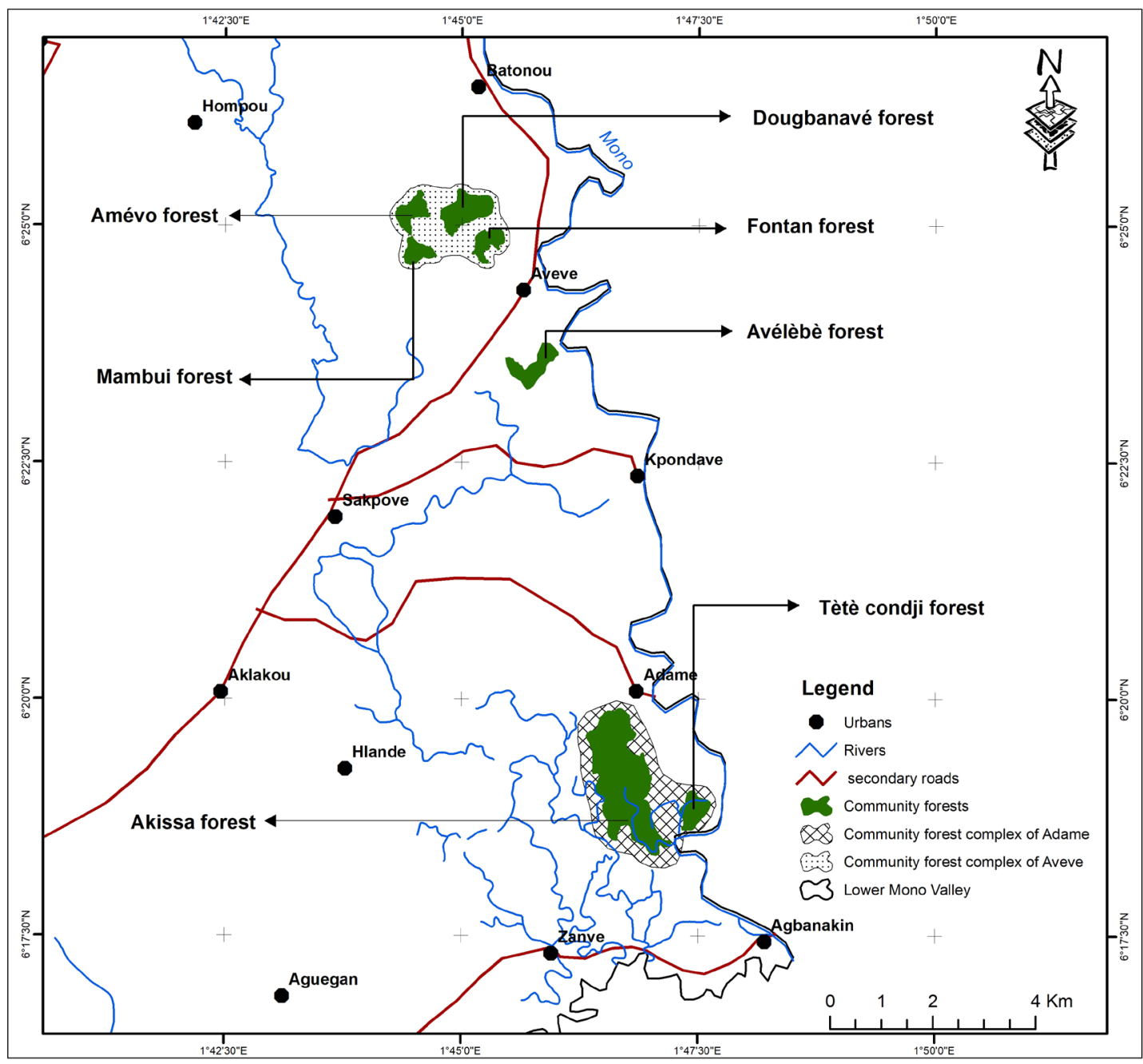

Figure 4. Geographic location of community forests of the LMV.

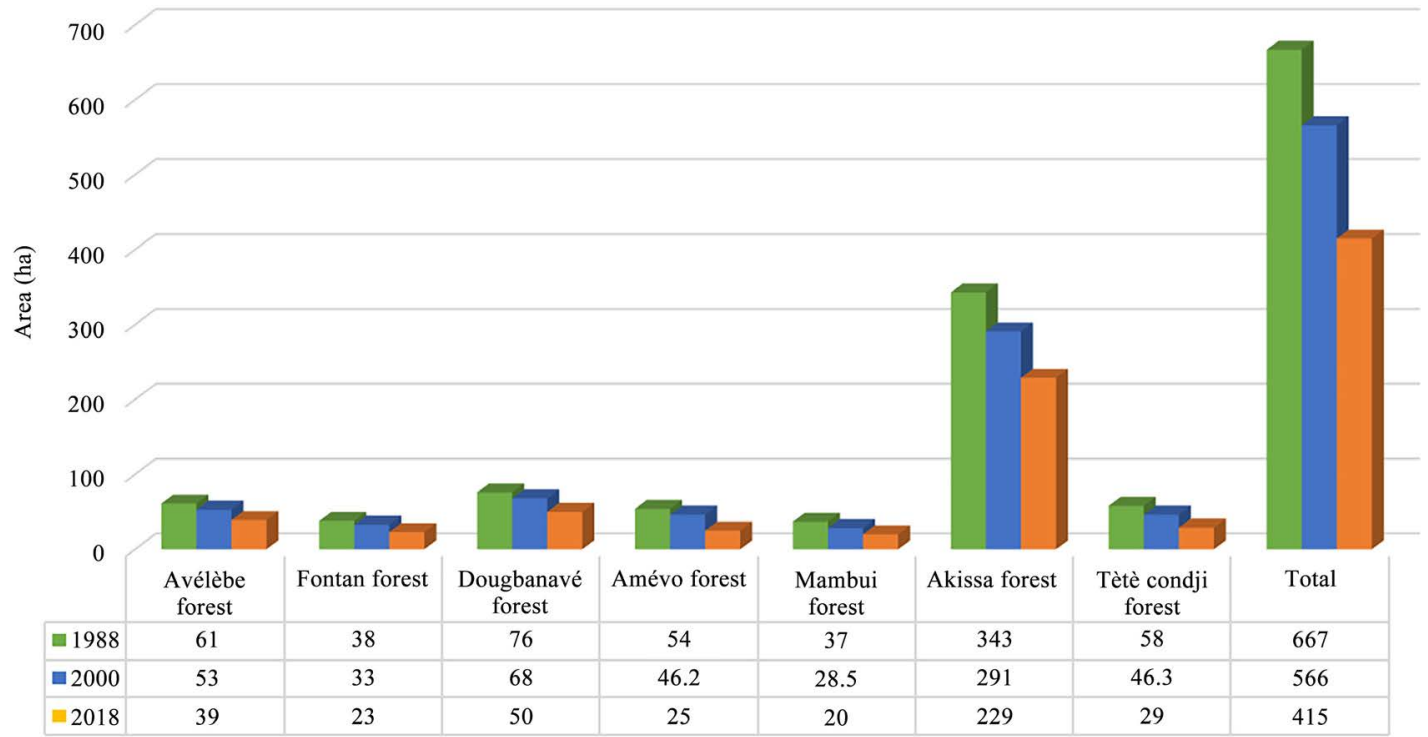

Figure 5. Breakdown of community forest areas in the LMV from 1988 to 2018. 
of community forests in 1988, only 566 ha remain in 2000 and 415 ha in 2018 , i.e. $37.78 \%$ of loss in forest area over 30 years. The corresponding annual deforestation rate is $1.64 \%$ (Table 6). Tètè Condji, Amévo and Manbui forests have the highest annual deforestation rates compared to the other forests.

\section{Discussion}

This study was based on multi-source satellite images. The Sentinel 2A MSI images with a spatial resolution of bands ranging from 10 to $60 \mathrm{~m}$ allowed the identification and characterization of the current state of the resources of South-East Togo while Landsat TM and ETM+ images of $30 \mathrm{~m}$ spatial resolution were used as historical data to allow spatio-temporal monitoring. Although these images came from different sensors, it was very beneficial to bring them together for the characterization and the spatio-temporal monitoring of the landscape. However, it is important to note that the MSI sensor rendered scenes better than the TM and ETM+ sensors [18].

The results of visual interpretation of the sentinel-1A radar images helped to obtain complementary information relative to the landscape, according to the seasons of the year and the polarization (VV, VH) of the Sentinel-1A platform. However, some difficulties were encountered in the discrimination of land use units based on the VV and VH polarized images at full spatial resolution. In fact, since these images were not filtered, the presence of speckles did not allow an easy discrimination of the land use units. On the other hand, on the filtered images, the color composite images allowed a better identification of land use classes compared to $\mathrm{VV}$ and $\mathrm{VH}$ polarized images and resultant images ( $\mathrm{VV}+\mathrm{VH}$ ).

The coupling of Optical and Radar images was highly beneficial in this study owing to their complementarity. For instance, Radar images allowed a better identification of forest cover, whereas optical images performed well in identifying urban areas. We therefore strongly recommend the coupling of both sources of data.

Table 6. Annual rate of deforestation in community forests.

\begin{tabular}{cccc}
\hline & \multicolumn{3}{c}{ Annual rate of deforestation (\%) } \\
\hline Forests names & $1988-2000$ & $2000-2018$ & $1988-2018$ \\
Avélèbè forest & 1.17 & 1.80 & 1.54 \\
Fontan forest & 1.18 & 2.12 & 1.73 \\
Dougbanavé forest & 0.93 & 1.81 & 2.66 \\
Amévo forest & 1.30 & 3.61 & 2.12 \\
Mambui forest & 2.18 & 2.08 & 1.39 \\
Akissa forest & 1.37 & 1.41 & 2.39 \\
Tètè Condji forest & 1.88 & 2.75 & 1.64 \\
\hline Total & 1.37 & 1.83 & \\
\hline
\end{tabular}


The quality control of the classification of optical images TM, ETM+ and MSI gave an overall accuracy of $84.54 \%, 86.31 \%$ and $91.57 \%$ respectively. The calculated Kappa index (K) was 0.81, 0.83 and 0.9 for the years 1988, 2000 and 2018 respectively. Therefore, based on the scale of Landis and Koch [21], the classification can be said excellent $(K>0.8)$ and the results are exploitable.

The spatial analysis revealed a changing spatial structure. The increase in area of water bodies, swamps and riparian formations could be explained by the fact that a considerable part of the Lower Mono Valley is often flooded by floodwaters from the Mono River during rainy seasons. In addition, the pedology of the area predominated by vertisols [8] does not favor enough infiltration of rainwater, leading to stagnation and runoff and causing flood and erosion. The expansion of urban areas reflects the construction of new housings and infrastructures. The study of [24] on this region also showed an annual growth of $2.01 \%$ for urban areas and $1.02 \%$ for water bodies. Concerning the decrease in area of savannahs, we observed in the southeastern part of the study area that savannahs were grazed, which led to soil compaction by cattle and their transformation into marshy and/or floodable zones. In the center of the study area, savannahs are being converted into plantation (e.g. coconut and palm groves). The decrease in area of crops and fallows is explained by the rural exodus phenomenon, which led to farmland abandonment and subsequent conversion into plantations.

The CFs that were identified and mapped represent majestic examples of forest in the area. They provide ecosystem services (timber and non-timber forest products collection, regulatory, cultural, and self-maintenance services) which are essential for local populations. This said, the CFs of the Lower Mono Valley constitute a development pool in economic, social, cultural and environmental terms. However, the area analysis revealed that they are being overexploited by local people, leading to a rapid decline. In fact, out of 667 ha of CF in 1988, only 415 ha remain in 2018 , i.e. $37.78 \%$ of lost in forest area, which means an annual rate of deforestation of $1.64 \%$. At this alarming rate of deforestation, there would be no more community forests in half a century if no action is taken. The proximity of the community forests to two identified agglomeration complexes also suggests that they once formed the same forest unit, which might have been fragmented and degraded because of human activities. The main factors of degradation include the uncontrolled exploitation of wood resources (timber, fuelwood, charcoal) and non-wood products (animals, medicinal plants, etc.), bush fires for the practice of agriculture and hunting. Several authors have proved that the regular return of fire does not favor the reconstitution of the original vegetation [25] [26] [27]. This leads to a loss of biodiversity and consequently an important change in the structure and composition of the vegetation through the installation of herbaceous species [28] [29]. The study of [30] on the sacred forests of the lower Mono Valley has also shown that conflicts in this area (population growth, uncontrolled expansion of housing, erosion of religious beliefs and current weakness of power of religious leaders) weakened resource 
management systems that local people developed and conserved throughout generations. For these reasons, the resources suffer rapid and massive degradation leading to the reduction in their area or their near disappearance.

\section{Conclusion}

The present study aimed to provide the basics needed to reconcile the fight against poverty with the need of a good management of community resources in the context of local and sustainable development. It focused on the identification of geographic location and spatio-temporal dynamics of these resources in the southeastern part of Togo. Based on remote sensing techniques, this study helped to map the different land uses for the years 1988, 2000 and 2018. These maps will contribute to resource localization and preservation of sensitive areas. In other terms, they will be used for an integrated and rational management of resources in the Lower Mono Valley. The different community forests that were identified and mapped represent potential management units on which managers can rely for the development of management plans.

\section{Acknowledgements}

We thank the three reviewers that contributed in the improvement of the earlier version of this document. We thank as well the NGO APEDD-Togo that gave us their support for the field data collection.

\section{References}

[1] PNAE (2001) National Action Plan for the Environment. Ministry of the Environment and Forest Resources, Lomé, Togo.

[2] Courcelaud, A. (2000) Forest Resources of the Togodo Wildlife Reserve (South Togo): Dynamics and Diagnosis of Participatory Management. Master Thesis, Training of Forest Engineers, ENGREF, Montpellier, France.

[3] Kokou, K. (1998) Forest Mosaics in Southern Togo: Biodiversity, Dynamics and Human Activities. Doctoral Thesis, University of Montpellier II, France.

[4] Akpagana, K. (1989) Research on Dense and Humid Forests in Togo. Doctoral Thesis, University of Bordeaux III, France.

[5] MERF (2011) National Forest Action Plan of Togo-Phase1 (PAFN 1-TOGO) 2011-2019.

[6] Hubert, N.M. (2013) Community Forest Management Facing the Challenge of Poverty and Rural Development. Vertigo-la revue électronique en sciences de Penvironnement, 13, 1-8.

[7] Vermeulen, C., Vandenhaute, M., Dethier, M., Ekodeck, H., Nguenang, G.M. and Delvingt, W. (2006) From Kompia to Djolempoum: On the Tortuous Paths of the Development and Exploitation of Community Forests in Cameroon. Vertigo-la revue électronique en sciences de P environnement, 7, 1-8.

[8] FAO (1997) Forest Resources Assessment, Tropical Countries. FAO Forestry Paper No. 112. Rome, Italy.

[9] Brockmann, C. (2017) SNAP Software, Array Systems Computing and C-S. 
http://www.step.esa.int/main/toolboxes/snap/\#

[10] Rouse, J.W., Haas, R.H., Schell, J.A., Deering, D. and Harlan, J. (1973) Monitoring the Vernal Advancement of Retrogradation of Natural Vegetation. NASA/GSFC, Type III, Final Report, Greenbelt, MD, USA.

[11] Gao, B.C. and Goetz, A.F.H. (1995) Retrieval of Equivalent Water Thickness and Information Related to Biochemical Components of Vegetation Canopies from AVIRIS Data. Remote Sensing of Environment, 52, 155-162. https://doi.org/10.1016/0034-4257(95)00039-4

[12] Lee, J., Grunes, M. and Grandi, G. (1999) Polarimetric SAR Speckle Filtering and Its Implication for Classification. IEEE Transactions on Geoscience and Remote Sensing, 37, 2363-2373. https://doi.org/10.1109/36.789635

[13] Chen, B., Xiao, X., Li, X., Pan, L., Doughty, R., Jun Ma, J., Dong, J., Qin, Y., Zhao, B., Wu, Z., Sun, R., Lan, G., Xie, G., Clinton, N. and Giri, C. (2017) A Mangrove Forest Map of China in 2015: Analysis of Time Series Landsat 7/8 and Sentinel-1A Imagery in Google Earth Engine Cloud Computing Platform. Journal of Photogrammetry and Remote Sensing, 131, 104-120.

[14] Aubréville, A. (1958) In Search of the Ivory Coast Forest. Bois et Forêts des Tropiques, 57, 16-84.

[15] Noumonvi, K.D., Mounir, F. and Belghazi, B. (2017) Spatial Multi-Criteria Based Analysis to Assess Dynamics and Vulnerability of Forest Ecosystems to Global Changes: Case of Maamora Forest-Morocco. Open Access Library Journal, 4, e3889. https://doi.org/10.4236/oalib.1103889

[16] Shao, Y. and Lunetta, R.S. (2012) Comparison of Support Vector Machine, Neural Network and CART Algorithms for the Land-Cover Classification Using Limited Training Data Points. Photogrammetry and Remote Sensing, 70, 78-87. https://doi.org/10.1016/j.isprsjprs.2012.04.001

[17] McNairn, H., Champagne, C., Shang, J., Holmstrom, S. and Reichert, G. (2009) Integration of Optical and Synthetic Aperture Radar (SAR) Imagery for Delivering Operational Annual Crop Inventories. Photogrammetry and Remote Sensing, 64, 434-449. https://doi.org/10.1016/j.isprsjprs.2008.07.006

[18] Konko, Y., Bagaram, B., Julien, F., Akpamou, K.G. and Kokou, K. (2018) Multitemporal Analysis of Coastal Erosion Based on Multisource Satellite Images in the South of the Mono Transboundary Biosphere Reserve in Togo (West Africa). Open Access Library Journal, 5, e4526. https://doi.org/10.4236/oalib.1104526

[19] Kenny, D.A., Kashy, D.A. and Cook, W.L. (2006) Dyadic Data Analysis. Guilford Press, New York.

[20] Lucas, L., Janssen, F. and Frans, J.M. (1994) Accuracy Assessment of Satellite Derived Land-Cover Data: A Review. Photogrammetric Engineering \& Remote Sensing, 4, 479-426.

[21] Landis, J.R. and Koch, G.G. (1977) The Measurement of Observer Agreement for Categorical Data. Biometrics, 33, 159-174. https://doi.org/10.2307/2529310

[22] Adjonou, K., Djiwa, O., Kombate, Y., Kokutse, A.D. and Kokou, K. (2010) Study of the Spatial Dynamics and Structure of Dry Relict Forests of Togo: Implications for Sustainable Management of Protected Areas. International Journal of Biological and Chemical Sciences, 4, 168-183.

[23] Puyravaud, J.P. (2002) Standardizing the Calculation of the Annual Rate of Deforestation. Forest Ecology and Management, 177, 593-596.

https://doi.org/10.1016/S0378-1127(02)00335-3 
[24] Konko, Y. (2016) Contribution of Remote Sensing and GIS to the Integrated Management of Community Forest Resources in the Bas-Mono Valley (South-East Togo). Master Thesis, Post University Regional School of Integrated Management of Tropical Forests and Territories, Kinshasa.

[25] Kanvaly, D.S., Konaté, A.T.M., Kouakou, M., Dembélé, A., Aïdara, D. and Linsenmair, K.E. (2011) Can Unburned Savanna Sections Serve as Temporary Refuges for Insects? An Experiment in a Tropical Humid Savanna in Côte d'Ivoire. Journal of Applied Biosciences, 84, 67-79.

[26] Devineau, J.L., Fournier, A. and Nignan, S. (2010) Savanna Fire Regimes Assessment with MODIS Fire Data: Their Relationship to Land Cover and Plant Species Distribution in Western Burkina Faso (West Africa). Journal of Arid Environments, 74, 1092-1101. https://doi.org/10.1016/j.jaridenv.2010.03.009

[27] Archibald, S. (2008) Where There Is a Spark Is There Fire? The Importance of Ignitions in Determining Fire Regimes in Southern Africa. South African Journal of Botany, 74, 360-365. https://doi.org/10.1016/j.sajb.2008.01.028

[28] Afelu, B., Fontodji, K.J. and Kokou, K. (2016) Impact of Fires on Biomass in the Guinean Sudanese Savannahs of Togo. VertigO-la revue électronique en sciences de Penvironnement, 6, 1-9.

[29] Tabarelli, M., Lopes, A. and Peres, C. (2008) Edgeeffects Drive Forest Fragments towards an Early-Successional System. Biotropica, 40, 657-661. https://doi.org/10.1111/j.1744-7429.2008.00454.x

[30] Kokou, K., Caballé, G. and Akpagana, K. (1999b) Floristic Analysis of Forest Patches in Southern Togo. ActaBotanica Gallica, 146, 139-144.

https://doi.org/10.1080/12538078.1999.10515812 